\title{
Differences in Functional Trait Distribution between Inselberg and Adjacent Matrix Floras
}

\author{
John T. Hunter \\ School of Environmental and Rural Science, University of New England, Armidale, Australia \\ Correspondence should be addressed to John T. Hunter; jhunter8@bigpond.com
}

Received 30 June 2016; Accepted 26 September 2016

Academic Editor: Béla Tóthmérész

Copyright ( 92016 John T. Hunter. This is an open access article distributed under the Creative Commons Attribution License, which permits unrestricted use, distribution, and reproduction in any medium, provided the original work is properly cited.

\begin{abstract}
Inselbergs and the adjacent matrix represent extremes of different environmental conditions and should shed light on the changing allocation of plant resources across strong and abrupt resource gradients. Here I use collated life history trait data from 840 taxa found within typical insular inselberg and adjacent matrix floras from the New England Batholith region of eastern Australia. These species were sorted into guilds of specificity to the inselberg environment. Scored traits include life form, plant height, leaf area, fruit size, seed size, mono- or polycarpy, underground storage organs, regenerative/clonality, and flowering phenology. With reduced water and nutrient resources, typical of inselbergs, allocation of plant resources to vegetative reproduction and storage organs is a disadvantage. Plants restricted to inselbergs were shorter, usually polycarpic shrubs, with smaller leaves, fruits, and seeds. Flowering time was found to be earlier and reduced in length; diaspores often have dormancy and are dispersed locally in comparison to the matrix. The results show that with limited resources the creation of underground storage organs or vegetative reproduction becomes unviable on habitats characterised by shallow soil. Inselberg taxa of the study region are likely to be under greater threat than the matrix due to anthropogenic climate change.
\end{abstract}

\section{Introduction}

Central to functional ecology is the ability to link changes in species traits to ecosystem processes [1]. The distribution of functional traits is linked to the unique key evolutionary, environmental, predation, and competition pressures within a community. Functional traits determine how resources are secured and how those resources are allocated and/or stored, determining how species persist, compete, disperse, coexist, and reduce loss from herbivory [2-6]. Comparisons of trait differences between community types can allow for a more nuanced understanding of how traits and taxa may redistribute under global climate change [6]. However, selection acts on individuals and not on individual traits themselves indicating that it is a suite of coordinated traits that influence persistence, regeneration, and dispersal [7-9].

While functional trait investigations are increasingly common, comparisons between the floras of adjacent but contrasting environments are lacking. Granitic inselberg environments offer "habitat islands" that contrast dramatically from the surrounding vegetated matrix and have a worldwide distribution with replicate geomorphological structure [10-13]. Inselbergs are harsher and drier environments compared to the matrix in which they are embedded. Inselbergs shed up to $95 \%$ of precipitation, the soils are skeletal, humic, and highly acidic [10, 12, 14-22]. Temperatures up to $18^{\circ} \mathrm{C}$ higher than the ambient air and in excess of $60^{\circ} \mathrm{C}$ within the soil have been recorded; greater exposure to wind and solar radiation means that the thin soils rapidly dry out $[16,20,22-25]$. The vegetation around adjacent to the base of inselbergs receives increased moisture from runoff and nitrogen loads from inselberg biofilms [26]. Büdel et al. [26] showed that nitrogen content in the matrix soils adjacent to inselbergs was three times higher than the surrounding area. These characteristics are inherent features of inselbergs and their adjacent matrices worldwide [13].

As granitic inselbergs have a less favorable environment than the adjacent matrix in which they are imbedded, plants from such environments should develop persistence life history traits $[13,27]$. Species may persist in situ by increasing the longevity of above ground parts, by increasing the longevity of below ground parts or via dormancy 
mechanisms of diaspores [5, 7]. Benwell [28] and Clarke [29] suggested that vegetative reproduction (resprouting and clonality) was a stress tolerant regeneration strategy compensating for high-risk recruitment and such strategies should be more common in drought affected environments and thus favored on inselbergs. In contrast, Halassy et al. [30] provided evidence that species that put greater resources into vegetative reproduction and/or storage organs were favored under mesic, resource rich, and competitive environments. Taxa with shorter stature with larger seeds, smaller long-lived leaves, longer lifespan, and denser wood are more likely to occur within areas of low resource availability compared to taxa from resource rich environments [5-7, 9, 31-33].

Although inselbergs are ideal "habitat islands," how permeable the barrier is between environments varies considerably, and thus some inselbergs are effectively more floristically insular than others $[12,34]$. For example, within the New England Batholith of eastern Australia $76 \%$ of the granitic inselberg flora is shared with the surrounding matrix to varying degrees with overall endemism decreasing across the landscape with increasing landscape aridity [12]. McGann [12] created a set of guilds based on restriction to the inselberg environment and Hunter [13] used these in an investigation into the distribution of obligate seeding and resprouting life history traits on granitic inselbergs and within the adjacent matrix.

Many species are likely to be uninformative in cross community analyses as they are commonly shared taxa with similar abundances across both environments. Here, selected trait expressions between taxa with high specificity to the granitic inselberg environment of eastern Australia are compared to taxa with specificity to the immediate adjacent forested matrix based on the guilds of McGann [12]. Tested traits include plant height, specific leaf area, fruit size, seed size, life form, regenerative capacity, phenology, dormancy, and dispersal. Due to the contrasts between these adjacent vegetation types I hypothesized that inselberg endemics are likely to have long generation times, slow growth, and locally dispersed seeds and once established dominate spatial resources as occurring with other persistence niche specialists $[13,27]$.

\section{Methods}

2.1. Study Area. The New England Batholith lies in the north eastern corner of the state of New South Wales and the south eastern corner of the state of Queensland within Australia. The batholith extends for approximately $400 \mathrm{~km}$ north to south and $110 \mathrm{~km}$ east to west [35]. Elevations are highest on the eastern escarpment and fall towards the west. Surveyed areas varied in altitude from $310-1520 \mathrm{~m}$ above sea level. The vegetation on inselbergs in this region is largely of closed to open heaths, shrublands, or herbfields with the adjacent matrix comprised of rainforest, forest, and woodlands. Analysis of the relationships between the matrix and inselberg floras and detailed descriptions of the vegetation types, flora, and mapped distribution covered by this investigation are contained within Clarke et al. [36], Hunter and Clarke [37],
TABLE 1: Inselberg insular guilds as defined by McGann [12].

\begin{tabular}{ll}
\hline Guild & Category of insularity \\
\hline 0 & $\begin{array}{l}\text { Never found on inselbergs, taxa restricted to the } \\
\text { surrounding vegetation } \\
\text { Taxa always found in surrounding matrix but in } \\
\text { low abundance on inselbergs }\end{array}$ \\
Ubiquitous taxa found equally on inselbergs or \\
the matrix \\
Taxa common on inselbergs but occasionally \\
found in the surrounding matrix \\
Taxa restricted to inselbergs on the New England \\
4 & $\begin{array}{l}\text { Batholith but found in other habitats elsewhere } \\
\text { Taxa restricted to inselbergs and other rock } \\
\text { outcrops throughout their distribution } \\
\text { Taxa restricted to granitic inselbergs throughout } \\
\text { their distribution }\end{array}$ \\
\hline
\end{tabular}

Hunter et al. [38, 39], J. T. Hunter and V. H. Hunter [40], Hunter [41], Hunter [42], and Hunter and Sheringham [43].

Rainfall is seasonal and occurs mostly in summer (60$70 \%)$ with snow occurring occasionally at higher altitudes (Bureau of Meteorology http://www.bom.gov.au/). Rainfall ranges from 600 to $1000 \mathrm{~mm}$ annually in the west and from 1000 to $2500 \mathrm{~mm}$ annually along the eastern escarpment (Bureau of Meteorology http://www.bom.gov.au/).

2.2. Survey Design. The survey was conducted using $32 \mathrm{~m}$ $\times 32 \mathrm{~m}$ (c. $0.1 \mathrm{ha})$ nested plots (9 nests; hence a relative abundance score out of 10 was derived for each species within each plot) [44] and collected solely by the author. A total of 399 plots were allocated to 216 inselbergs and 123 plots were placed within the surrounding forested matrix. Full details of the survey procedure and the stratification of sites are given in Hunter and Clarke [37]. In total 840 vascular plant taxa were found within plots during April 1994 to June 1996.

2.3. Soil $\mathrm{pH}$ Determination. The $\mathrm{pH}$ of both matrix and inselberg soils were tested at each site. The "1:5 Soil/Water suspension method" of Raymont and Higginson [45] was used for determining soil pH. $20.00 \mathrm{~g}$ of air-dry soil and $100 \mathrm{~mL}$ of deionized water were placed within jars and tumble within a mechanical tumbler for one hour at room temperature. Solutions were allowed to settle for 30 mins. Electrodes of a standardized $\mathrm{pH}$ meter were placed within solutions that were mechanically stirred until the reading settled. After each measurement electrodes were washed with deionized water. Replicate determinations were periodically made on the same solutions to ensure that readings did not vary within samples by more than $0.1 \mathrm{pH}$.

2.4. Statistical Methods. Taxon related tables were created that included information on species relative abundance (out of 10) within each quadrat, a table of life form and life history traits for each species and a table scoring each species within one of the seven inselberg insular guilds (as scored by McGann [12], Table 1). The community based 
technique of Community Weighted Means of traits [46] was applied to assess the response of functional traits within floristic inselberg insular guilds. Trait expressions of all species were weighted by their relative abundances from each plot. A redundancy analysis was then performed on the plot by trait matrix constrained by the table created from the summed relative abundances of each insular guild via the CANOCO5 package [47]. Thus, functional traits are assessed across the gradients of insularity/endemicity to the inselberg environment as expressed by the insular guilds. Traits recorded for each of the 840 flora taxa included the following: trait scores were based on maximum values along with life form type scored from localized collections obtained by the author and those from the region housed within the NCW Beadle Herbarium at the University of New England for each taxon. Some additional information was also obtained from PlantNET (http://plantnet.rbgsyd.nsw.gov.au/; accessed October 2014). Values allocated to each of the 840 vascular species included plant height, leaf area (length by width), fruit size (length by width), fruit type (dry dehiscent, dry indehiscent, legume, and succulent), seed size (length by width), monocarpic or polycarpic, presence or absence of storage organs (e.g., bulbs, tubers, swollen taproots, corms, and lignotubers), and vegetative spread capacity (e.g., rhizomes, runners, stolons, suckering, and rooting at nodes).

Life form types were also attributed to each taxon and these included hemiparasites, lianas and vines, herbs, low shrubs, medium shrubs, tall shrubs, low trees, medium trees, and tall trees. Dispersal syndromes and propagule attachments were also recorded for each species and from these data each species was scored for the capacity to be transported more than 100. This was done based on the criteria of Elizabeth [7] whereby large, gravity dispersed propagules were considered to be locally dispersed only and scored as "none." Ant-dispersed or medium sized propagules were scored as "limited" due to their likely medial dispersal distance. Propagules were scored as "strong" for long distance dispersal if they possessed structures that enable wind or animal dispersal [7]. Similarly the capacity for diaspore dormancy was also scored in the same fashion for each taxon (i.e., no dormancy, limited dormancy, and strong dormancy). Comparisons between these life history attributes were made using percentage of the flora within each category. Flowering duration was coded by the maximum number of months for which a species has been recorded to flower. Comparisons between inselberg (guilds 5 or 6 ) and matrix floras (guilds 0 or 1) were made using univariate statistics after testing for normality of distribution and the differences tested using the Mann-Whitney test of significance using PAST 2.17b [48].

\section{Results}

For final presentation the RDA analysis was restricted to only the guild types (0-1 and 5-6). The explanatory variables accounted for $22.5 \%$ (test on all axes $p=0.002$ ) of the variance of functional traits (Figure 1). This analysis indicates that overall the functional traits of smaller leaf size, lower height, a lack of underground storage organs, and lack of monocarpic

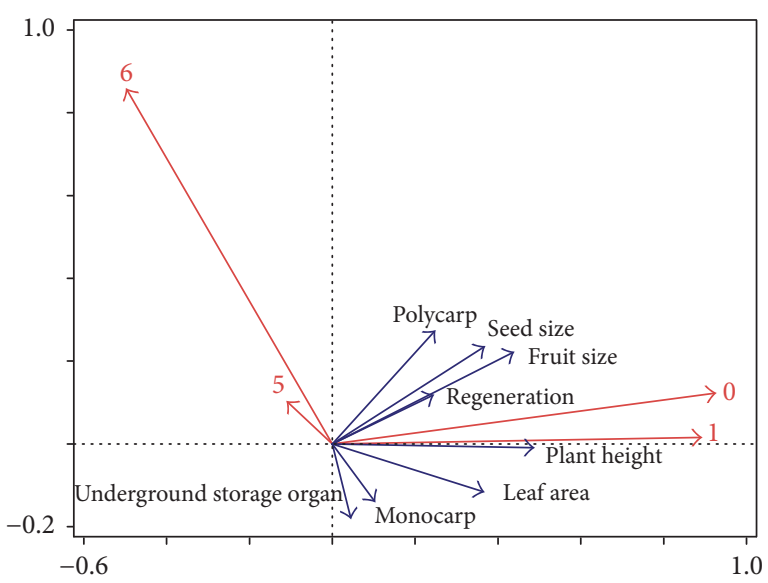

FIGURE 1: Redundancy analysis of the central weighted means of nine select functional traits of species found within the New England Batholith. Increasing number indicates increasing restriction to the inselberg environment (Table 1).

life history are favored by inselberg endemic flora species on the New England Batholith of eastern Australia. All guild "6" taxa (inselberg endemics) were polycarpic species as opposed to guild type "0" (matrix restricted species) which had the second highest percentage of monocarpic species $(13 \%)$. However, species from within the surrounding matrix are more likely to favor the traits of increased plant height, larger leaf area, larger seed, and fruit size.

The inselberg soils were significantly higher in acidity than the adjacent matrix. Soil $\mathrm{pH}$ mean was 4.4 on inselbergs (Std. error 0.02; 3.5 minimum recorded); in contrast matrix soils had a mean of 5.6 (Std. error 0.06) $(p=0.0001)$.

Table 2 presents the percent distribution of life form types across the insular guild categories. Categories with increasing restriction to the inselberg environment are more likely to be low shrubs with no representation within the medium to tall tree categories, as hemiparasites or lianas and vines. Herbs dominate floristic guilds one to three which represent species that are found within inselbergs and matrix floras.

In terms of diaspore distance dispersal there was a relatively even distribution between types within matrix taxa (Table 3; 66\% with some dispersal traits). In contrast, the majority of inselberg flora species (55\%) had no distance dispersal mechanisms (Table 3). No diaspore dormancy was the most common strategy for matrix flora species (63\%); however, there was an almost even distribution across the three dormancy types within the inselberg floras with most species having some form of diaspore dormancy (68\%) (Table 3).

Flowering times for both inselbergs and the matrix floras were concentrated within the spring and summer months between August and February. June had the lowest number of species known to flower in both environments; however, the peak flowering month was September for inselberg species and October for matrix species. On average inselberg floras flowered over 4.5 months (Std. error 0.35$)$ while matrix floras flowered for 5.1 months (Std. error 0.19) ( $p=0.048)$. 
TABLE 2: Percent of vascular flora within each major life form type from inselberg insularity guilds.

\begin{tabular}{lccccccccc}
\hline $\begin{array}{l}\text { Insularity } \\
\text { guild }\end{array}$ & Hemiparasites & $\begin{array}{c}\text { Lianas and } \\
\text { vines }\end{array}$ & Herbs & Low shrubs & Medium shrubs & Tall shrubs & Low trees & Medium trees & Tall trees \\
\hline 0 & 0 & 2.4 & 38.7 & 20.4 & 24.6 & 2.4 & 4.1 & 6.9 \\
1 & 0.2 & 9.6 & 53.4 & 21.6 & 5.0 & 3.5 & 0.0 & 6.5 \\
2 & 0.2 & 2.4 & 63.6 & 16.6 & 5.8 & 3.3 & 5.0 & 2.5 & 0.3 \\
3 & 0 & 0 & 80.9 & 24.3 & 3.2 & 0.0 & 0.2 & 0.4 & 0.0 \\
4 & 0 & 0 & 31.8 & 47.5 & 8.5 & 12.3 & 0 & 0 & 0 \\
5 & 0 & 0 & 31.8 & 47.5 & 8.5 & 12.3 & 0 & 0 & 0 \\
6 & 0 & 0 & 19.3 & 52.7 & 26.8 & 0.5 & 0.6 & 0 \\
\hline
\end{tabular}

TABLE 3: Percentage allocation of matrix (guild 0 or 1) and inselberg (guild 5 or 6) floras to dispersal and dormancy categories.

\begin{tabular}{lccc}
\hline Life history variable & None & Limited & Strong \\
\hline $\begin{array}{l}\text { Matrix flora diaspore distance } \\
\text { dispersal capacity }\end{array}$ & 33.8 & 36.7 & 29.5 \\
$\begin{array}{l}\text { Inselberg flora diaspore distance } \\
\text { dispersal capacity }\end{array}$ & 54.8 & 38.7 & 6.5 \\
$\begin{array}{l}\text { Matrix flora diaspore dormancy } \\
\begin{array}{l}\text { Inselberg flora diaspore } \\
\text { dormancy }\end{array}\end{array}$ & 62.5 & 29.1 & 8.7 \\
\hline
\end{tabular}

\section{Discussion}

The granitic inselberg environment is an arid nutrient poor habitat compared to the surrounding matrix and as expected these environmental factors have favored persistence niche characteristics of (smaller leaves and lower stature). However other suites of functional traits are not consistent (smaller seeds, fruits, lack of dispersal, no vegetative spread/clonality, and no underground storage organs) $[4,5,28,29,32,49]$.

4.1. Resource Limitation. The soils on inselbergs had significantly higher acidity which would limit the capacity of plants to acquire nutrients. In low $\mathrm{pH}$ soil nutrients are quickly leached reducing soil fertility which has been linked to reduced leaf and fruit size [9]. As expected matrix taxa were taller, had larger leaf area scores, and produced larger seeds and fruits. Such features are typical of habitats with greater moisture and nutrient availability, where competition is high, light is limiting, and predation may be higher $[8,33$, 50]. Hunter [13] suggested a model where competition for light was high in the matrix but that light was abundant on inselbergs and that predation/grazing was higher within the matrix of the New England Batholith; the results here support this model.

Resprouting/clonality traits were more commonly expressed within matrix species where nutrient and water resources were higher and climate more ameliorated. This provides support for Halassy et al. [30] who suggested that such species were favored in resource rich mesic environments with high competition and is at odds with Benwell [28] and Clarke [29] who proposed that such strategies were more likely to occur in locations of high stress and high recruitment risk.

4.2. Underground Storage Organs. The possession of underground storage organs was negatively associated with species specific to the inselberg environment, again indicating that such life history traits are of no advantage. Underground storage organs like diaspore dormancy can be a method of avoiding disadvantageous times by allowing above ground parts to die, yet allowing survival below ground enabling a rapid response when optimal conditions recur. Some form of diaspore dormancy was the norm for inselberg restricted taxa but lacking in most matrix species. However both fruits and seeds were smaller on inselbergs rather than larger as suggested by theory for harsh environments [49]. It is possible that the harsher conditions, lowered water, and nutrient availability on inselbergs or simply the reduced space on shallow soil basins do not favor the storage of additional resources (e.g., rhizomes, tubers, corms, bulbs, runners, and stolons) but instead there is selective pressure for diaspore dormancy in smaller rather than larger seeds. The combination of these traits would collectively reduce the need to capture greater resources from the impoverished soils. Alternatively, as inselbergs are deemed to have lower biomass removing disturbance events, yet juvenile mortality is still high (possibly through drought) [13] there is likely to be little advantage to the development of underground storage organs enabling quick growth following disturbances. The higher nutrient and water availability and ameliorated climate within the matrix along with more frequent biomass removing disturbances (fire and grazing) may select for vegetative reproduction and spread and more immediate regeneration as would be expected in highly competitive communities.

4.3. Persistence Niche. The shifting persistence niche hypothesis [51] proposes that the selective advantage of resprouting is bell shaped and changes along a gradient of disturbance. Hence where disturbances are infrequent resprouting is a disadvantage, under moderate disturbance it is advantageous but under frequent disturbance the ability to replenish bud 
resources diminishes, and it becomes a disadvantage $[52,53]$. It is possible that the same mechanisms are at play across a gradient of resource availability whereby the ability to store additional resources becomes disadvantageous under very high and very low resource availability (nutrients/water, etc.) and the strategy is of greatest benefit under medial resource availability when competition between species is greatest. However to test this hypothesis further additional nutrient environments would need to be added. It is unlikely that any trait is advantaged in a continual linear fashion to any resource gradient $[6,54]$.

4.4. Carpy. Monocarpy (semelparity) in herbaceous species is generally favored in situations where juvenile mortality is low and in situations of episodic and short-lived opportunities is created by disturbances $[7,32,55,56]$. Such taxa have small seeds and wider dispersal with larger geographic ranges $[56,57]$. Monocarpic herbaceous taxa tend to have many small seeds and are favored in high resource environments $[5,7]$. The lack of such taxa within inselberg restricted guilds suggests that juvenile mortality between reproductive events may be high and provides further evidence that dormancy in diaspores and local dispersal is of more selective advantage than smaller, dispersible seeds lacking longer term dormancy in harsher and resource limiting environments.

4.5. Phenology. Following the flowering phenology of two sister species, one restricted to inselbergs and the other within the adjacent matrix, Hunter and Williams [58] found that the inselberg restricted taxon flowered one month earlier than its matrix counterpart supporting the findings provided here. Hunter et al. [20] clearly showed that the temperature diurnal and seasonal range on inselbergs was much greater than the adjacent matrix and during summer periods could be over 10 degrees Celsius higher. Species may flower earlier on the inselbergs due to the earlier warming of these environments [59]. However, flowering is a physiologically expensive and the length of this phenophase is linked to optimal temperature ranges [60]. Thus, the significant reduced flowering period of approximately one month is potentially due to the physiological constraints on flowering being reached earlier on these exposed inselbergs with greater temperature amplitudes.

4.6. Adaptations of Inselberg Taxa. Overall the evidence supports the assumptions of Hunter [13] that inselberg restricted taxa are long-lived, locally dispersed and persist by dominating local limited resources. An unexpected discovery was that the lack of trait expressions associated with below ground storage and above ground vegetation spread suggesting that these traits are disadvantageous in these extreme and nutrient poor environments. Investigations by Poot et al. [61] suggest that inselberg endemics have adapted in a novel way by increasing their root mass and distributing it more evenly within the substrate. In agreement with Hunter [13] competition between inselberg flora species is strongest for the limited size of soil patches and the accessible nutrients and moisture within it.
4.7. Anthropogenic Climate Change. McGann [12] found the most significant correlated climatic factors with the occurrence of inselberg restricted species within the study region included a negative relationship with increased diurnal range, positive to increased precipitation of the driest quarter and negative to the maximum temperature of the wettest period. Predictions of global climate change indicate that within the study region the mean diurnal range will increase, precipitation of the driest quarter will decrease, and maximum temperature of the wettest period will increase [62-64]. All of which indicates that conditions are likely to cause potential extinctions of these rare, highly restricted inselberg species with long generation times and limited dispersal mechanisms in favor of more ubiquitous taxa shared by both environments. Thus, a significant reduction in local and regional diversity is lost increasing homogenization of the landscape. Other similar continental habitat islands (e.g., Kurgans of the Eurasian Steppe) are likely to share a similar fate.

\section{Conclusion}

Differences resource availability (nutrients and water) and climatic conditions have likely caused significant and different selective pressures on plant functional traits between species restricted to the inselberg environment and those within the adjacent matrix. The lack of resources and reduced habitability of the inselberg environment necessarily means that there is an inability or a disadvantage to the creation of underground storage organs and vegetative structures (rhizomes, runners, stolons, etc.) and that extended flowering is also problematic. Underground storage organs and vegetative structures can only be created where there are sufficient accessible resources (including space) and are likely favored under competitive environments with greater chances of biomass removing disturbances. The restrictions of the inselberg environment also limit the height of plants, size of leaves, fruits, and seeds. The effect of global climate change within the New England Batholith is likely to see a reduction or extinction in the unique and rare inselberg restricted species. This study has highlighted the need to address the differences between adjacent habitat types by removing shared species in order to better understand key divergence in functional traits. It is highly likely that endemic species of habitat islands with similarly specialized functional traits and poor dispersal will be under greater extinction threat than those within the surrounding matrix.

\section{Competing Interests}

The author declares that they have no competing interests.

\section{Acknowledgments}

The original survey sites were placed during a $\mathrm{Ph}$. D. program funded by an Australia Postgraduate Award at the University of New England. The collation of additional life history 
data and the extension of the original research have been conducted independently of funding sources.

\section{References}

[1] S. Lavorel and E. Garnier, "Predicting changes in community composition and ecosystem functioning from plant traits: revisiting the Holy Grail," Functional Ecology, vol. 16, no. 5, pp. 545-556, 2002.

[2] M. Aiba and T. Nakashizuka, "Architectural differences associated with adult stature and wood density in 30 temperate tree species," Functional Ecology, vol. 23, no. 2, pp. 265-273, 2009.

[3] D. Carmona, M. J. Lajeunesse, and M. T. J. Johnson, "Plant traits that predict resistance to herbivores," Functional Ecology, vol. 25, no. 2, pp. 358-367, 2011.

[4] M. Kleyer, S. Dray, F. de Bello et al., "Assessing species and community functional responses to environmental gradients: which multivariate methods?" Journal of Vegetation Science, vol. 23, no. 5, pp. 805-821, 2012.

[5] P. B. Adler, R. Salguero-Gómez, A. Compagnoni et al., "Functional traits explain variation in plant life history strategies," Proceedings of the National Academy of Sciences of the United States of America, vol. 111, no. 2, pp. 740-745, 2014.

[6] J. T. Hunter, "Changes in allometric attributes and biomass of forests and woodlands across an altitudinal and rainfall gradient: what are the implications of increasing seasonality due to anthropogenic climate change?" International Journal of Ecology, vol. 2015, Article ID 208975, 10 pages, 2015.

[7] J. F. Elizabeth, "Plant life history traits of rare versus frequent plant taxa of sandplains: implications for research and management trials," Biological Conservation, vol. 136, no. 1, pp. 44-52, 2007.

[8] M. Kleyer, R. M. Bekker, I. C. Knevel et al., “The LEDA traitbase: a database of life-history traits of the Northwest European Flora," Journal of Ecology, vol. 96, no. 6, pp. 1266-1274, 2008.

[9] S. P. Bonser, B. Ladd, K. Monro, M. D. Hall, and M. A. Forster, "The adaptive value of functional and life-history traits across fertility treatments in an annual plant," Annals of Botany, vol. 106, no. 6, pp. 979-988, 2010.

[10] S. Porembski, W. Barthlott, S. Dörrstock, and N. Biedinger, "Vegetation of rock outcrops in Guinea: granite inselbergs, sandstone table mountains and ferricretes-remarks on species numbers and endemism," Flora, vol. 189, no. 4, pp. 315-326, 1994.

[11] A. Gröger and W. Barthlott, "Biogeography and diversity of the inselberg (Laja) vegetation of southern Venezuela," Biodiversity Letters, vol. 3, no. 6, pp. 165-179, 1996.

[12] T. D. McGann, "How insular are ecological 'islands'? An example from the granitic outcrops of the New England Batholith of Australia," Proceedings of the Royal Society of Queensland, vol. 110, pp. 1-13, 2002.

[13] J. T. Hunter, "Persistence on inselbergs: the role of obligate seeders and resprouters," Journal of Biogeography, vol. 30, no. 4, pp. 497-510, 2003.

[14] S. D. Hopper, "Honeyeaters and their winter food plants on granite rocks in the central wheatbelt of Western Australia," Australian Wildlife Research, vol. 8, no. 1, pp. 187-197, 1981.

[15] D. L. Phillips, "Succession in granite outcrop shrub-tree communities," The American Midland Naturalist, vol. 106, no. 2, pp. 313-317, 1981.
[16] J. M. Baskin and C. C. Baskin, "Endemism in rock outcrop plant communities of unglaciated eastern United States: an evaluation of the roles of the edaphic, genetic and light factors," Journal of Biogeography, vol. 15, no. 5-6, pp. 829-840, 1988.

[17] G. Houle and A. Delwaide, "Population structure and growthstress relationship of Pinus taeda in rock outcrop habitats," Journal of Vegetation Science, vol. 2, no. 1, pp. 47-58, 1991.

[18] S. Ware, "Influence of interspecific competition, light and moisture levels on growth of rock outcrop Talinum (Portulacaceae)," Bulletin of the Torrey Botanical Club, vol. 118, no. 1, pp. 1-5, 1991.

[19] A. Burke, N. Jürgens, and M. K. Seely, "Floristic affinities of an inselberg archipelago in the southern Namib desert-relic of the past, centre of endemism or nothing special?" Journal of Biogeography, vol. 25, no. 2, pp. 311-317, 1998.

[20] J. T. Hunter, E. Fallavollita, and V. H. Hunter, "Observations on the ecology of Muehlenbeckia costata m.s. (Polygonaceae), a rare fire-ephemeral species occurring on the New England Batholith of northern New South Wales and southern Queensland," Victorian Naturalist, vol. 115, pp. 9-17, 1998.

[21] S. Lawler, S. Brown, G. Edney, S. Howelett, and P. Love, "Buffalo sallee at the back wall: an alpine species adapted to fire and drought," Victorian Naturalist, vol. 115, pp. 201-205, 1998.

[22] J. Szarzynski, "Xeric islands: environmental conditions on inselbergs," in Inselbergs: Biotic Diversity of Isolated Rock Outcrops in Tropical and Temperate Regions, S. Porembski and W. Barthlott, Eds., pp. 37-48, Springer, Berlin, Germany, 2000.

[23] G. S. Winterringer and A. G. Vestal, "Rock-Ledge vegetation in southern Illinois," Ecological Monographs, vol. 26, no. 2, pp. 105130, 1956.

[24] W. H. Murdy, T. M. Johnson, and V. K. Wright, "Competitive replacement of Talinum mangesii by $T$. teretifolium in granite outcrop communities," Botanical Gazette, vol. 131, pp. 186-192, 1970.

[25] D. J. Shure and H. L. Ragsdale, "Patterns of primary succession on granite outcrop surfaces," Ecology, vol. 58, no. 5, pp. 9931006, 1977.

[26] B. Büdel, U. Becker, G. Gollmann, and K. Sterflinger, "Algae, fungi and lichens on inselbergs," in Inselbergs: Biotic Diversity of Isolated Rock Outcrops in Tropical and Temperate Regions, S. Porembski and W. Barthlott, Eds., pp. 69-90, Springer, Berlin, Germany, 2000.

[27] W. J. Bond and J. J. Midgley, "Ecology of sprouting in woody plants: the persistence niche," Trends in Ecology and Evolution, vol. 16, no. 1, pp. 45-51, 2001.

[28] A. S. Benwell, "Post-fire seedling recruitment in coastal heathland in relation to regeneration strategy and habitat," Australian Journal of Botany, vol. 46, no. 1, pp. 75-101, 1998.

[29] P. J. Clarke, "Habitat insularity and fire response traits: evidence from a sclerophyll archipelago," Oecologia, vol. 132, no. 4, pp. 582-591, 2002.

[30] M. Halassy, G. Campetella, R. Canullo, and L. Mucina, "Patterns of functional clonal traits and clonal growth modes in contrasting grasslands in the central Appennines, Italy," Journal of Vegetation Science, vol. 16, pp. 29-36, 2005.

[31] M. Westoby, D. S. Falster, A. T. Moles, P. A. Vesk, and I. J. Wright, "Plant ecological strategies: some leading dimensions of variation between species," Annual Review of Ecology and Systematics, vol. 33, pp. 125-159, 2002.

[32] T. A. Forbis and D. F. Doak, "Seedling establishment and life history trade-offs in alpine plants," American Journal of Botany, vol. 91, no. 7, pp. 1147-1153, 2004. 
[33] J. W. F. Slik, S.-I. Aiba, F. Q. Brearley et al., "Environmental correlates of tree biomass, basal area, wood specific gravity and stem density gradients in Borneo's tropical forests," Global Ecology and Biogeography, vol. 19, no. 1, pp. 50-60, 2010.

[34] S. K. Wiser and R. P. Buxton, "Context matters: matrix vegetation influences native and exotic species composition on habitat islands," Ecology, vol. 89, no. 2, pp. 380-391, 2008.

[35] C. Leigh, "The form and evolution of Bald Rock, New South Wales," The Australian Geographer, vol. 10, no. 5, pp. 333-345, 1968.

[36] P. J. Clarke, L. M. Copeland, J. T. Hunter, C. E. Nano, J. B. Williams, and K. E. Willis, The Vegetation and Plant Species of Torrington State Recreation Area, Division of Botany, University of New England, Armidale, Australia, 1998.

[37] J. T. Hunter and P. J. Clarke, "The vegetation of granitic outcrop communities of the New England Batholith of eastern Australia," Cunninghamia, vol. 5, pp. 547-618, 1998.

[38] J. T. Hunter, J. Kingston, and P. J. Croft, "Vegetation and floristics of Kwiambal National Park and surrounds, Ashford, New South Wales," Cunninghamia, vol. 6, pp. 351-378, 1999.

[39] J. T. Hunter, A. Wyatt, D. Hofmeyer, L. Brown, N. Barkwell, and N. J. Beresford-Smith, "Vegetation and floristics of the demon nature reserve, Tenterfield, New South Wales," Cunninghamia, vol. 6, pp. 331-350, 1999.

[40] J. T. Hunter and V. H. Hunter, "Vegetation of ironbark nature reserve and Bornhardtia voluntary conservation agreement, Northern Tablelands, New South Wales," Cunninghamia, vol. 8, pp. 93-110, 2003.

[41] J. T. Hunter, "Vegetation of basket swamp National Park, Northern Tablelands, New South Wales," Cunninghamia, vol. 8, pp. 453-466, 2004.

[42] JT. Hunter, "Vegetation and floristics of Warra National Park and Wattleridge Northern Tablelands," NSW. Cunninghamia, vol. 9, pp. 255-274, 2005.

[43] J. T. Hunter and P. Sheringham, "Vegetation and floristic diversity in Gibraltar Range and part of Washpool National Parks, New South Wales," Cunninghamia, vol. 10, pp. 434-479, 2008.

[44] R. K. Outhred, "Semi-quantitative sampling in vegetation survey," in Survey Methods for Nature Conservation, K. Myers, C. Margules, and I. Musto, Eds., vol. 1, pp. 87-100, CSIRO Division of Water and Land Resources, Canberra, Australia, 1984.

[45] C. E. Raymont and F. R. Higginson, Australian Laboratory Handbook of Soil and Water Chemical Method, Inkata Press, Melbourne, Australia, 1992.

[46] E. Garnier, S. Lavorel, P. Ansquer et al., "Assessing the effects of land-use change on plant traits, communities and ecosystem functioning in grasslands: a standardized methodology and lessons from an application to 11 European sites," Annals of Botany, vol. 99, no. 5, pp. 967-985, 2007.

[47] C. J. F. ter Braak and P. Šmilauer, CANOCO Reference Manual and Users Guide Software for Ordination (Version 5.0), Microcomputer Power, Ithaca, NY, USA, 2012.

[48] Ø. Hammer, D. A. T. Harper, and P. D. Ryan, "Past: paleontological statistics software package for education and data analysis," Palaeontologia Electronica, vol. 4, article 9, 2001.

[49] P. B. Adler, A. Fajardo, A. R. Kleinhesselink, and N. J. B. Kraft, "Trait-based tests of coexistence mechanisms," Ecology Letters, vol. 16, no. 10, pp. 1294-1306, 2013.

[50] A. L. Mack, "An advantage of large seed size: tolerating rather than succumbing to seed predators," Biotropica, vol. 30 , no. 4 , pp. 604-608, 1998.
[51] P. J. Clarke, D. M. Bell, and M. J. Lawes, “Testing the shifting persistence niche concept: plant resprouting along gradients of disturbance," The American Naturalist, vol. 185, no. 6, pp. 747755, 2015.

[52] P. Croft, J. T. Hunter, and N. Reid, "Depletion of regenerative bud resources during cyclic drought. What are the implications for fire management?" Ecological Management \& Restoration, vol. 8, no. 3, pp. 187-192, 2007.

[53] P. J. Croft, J. T. Hunter, and N. Reid, “Threat of frequent fire and drought for the rare wattle Acacia williamsiana J. T. Hunter: an experimental burn highlights implications for fire management," Ecological Management and Restoration, vol. 11, pp. 217-220, 2010.

[54] L. Baastrup-Spohr, K. Sand-Jensen, S. V. Nicolajsen, and H. H. Bruun, "From soaking wet to bone dry: predicting plant community composition along a steep hydrological gradient," Journal of Vegetation Science, vol. 26, no. 4, pp. 619-630, 2015.

[55] J. Silvertown, Introduction to Plant Population Ecology, Longman Scientific and Technical, New York, NY, USA, 2nd edition, 1987.

[56] R. Snell and L. W. Aarssen, "Life history traits in selfing versus outcrossing annuals: exploring the 'time-limitation' hypothesis for the fitness benefit of self-pollination," BMC Ecology, vol. 5, article 2, 2005.

[57] J. T. Hunter, "Factors affecting range size differences for plant species on rock outcrops in eastern Australia," Diversity and Distributions, vol. 9, no. 3, pp. 211-220, 2003.

[58] J. T. Hunter and J. B. Williams, "A new species of Brachyloma and three new subspecies of $B$. daphnoides (Epacridaceae) from south-eastern Australia," Telopea, vol. 6, pp. 1-7, 1994.

[59] D. Primack, C. Imbres, R. B. Primack, A. J. Miller-Rushing, and P. Del Tredici, "Herbarium specimens demonstrate earlier flowering times in response to warming in Boston," American Journal of Botany, vol. 91, no. 8, pp. 1260-1264, 2004.

[60] R. L. Specht and A. Specht, Australian Plant Communities: Dynamics of Structure, Growth and Biodiversity, Oxford University Press, Melbourne, Australia, 1999.

[61] P. Poot, S. D. Hopper, and J. M. H. van Diggelen, "Exploring rock fissures: does a specialized root morphology explain endemism on granite outcrops?" Annals of Botany, vol. 110, no. 2, pp. 291300, 2012.

[62] L. Hughes, "Climate change and Australia: trends, projections and impacts," Austral Ecology, vol. 28, no. 4, pp. 423-443, 2003.

[63] K. Hennessy, C. Page, K. McInnes, R. Jones, and A. Bathols, Climate Change in New South Wales. Part 1: Past Climate Variability and Projected Changes in Average Climate, CSIRO, Australian Government Bureau of Meteorology, Canberra, Australia, 2004.

[64] PMSEIC Independent Working Group, "Climate change in Australia: regional impacts and adaptation-managing risk for Australia," Tech. Rep., Prime Minister's Science, Engineering and Innovation Council, Canberra, Australia, 2007. 

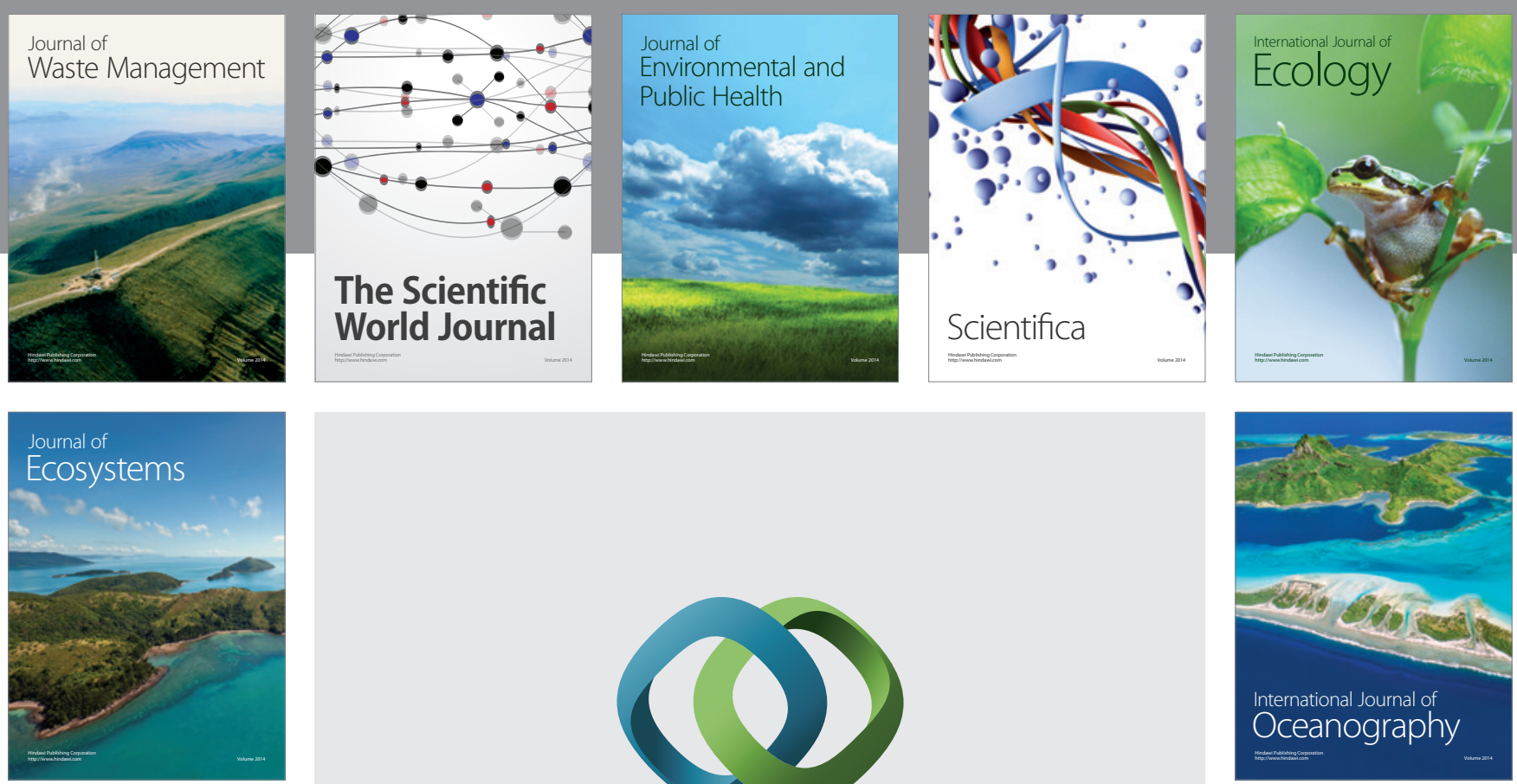

The Scientific World Journal
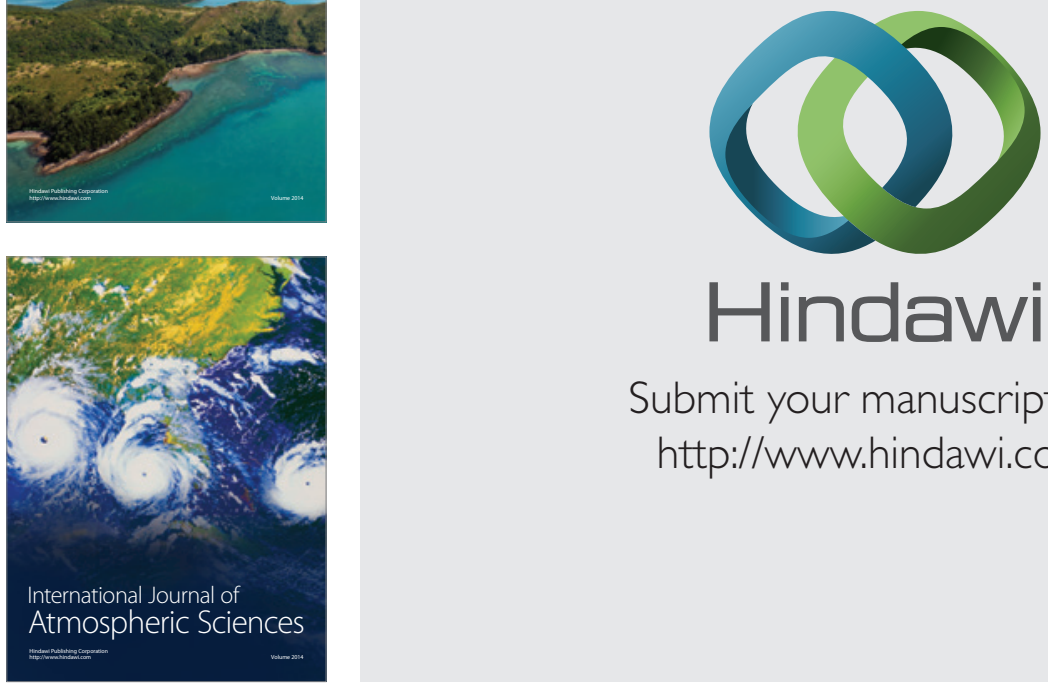

\section{Hindawi}

Submit your manuscripts at

http://www.hindawi.com
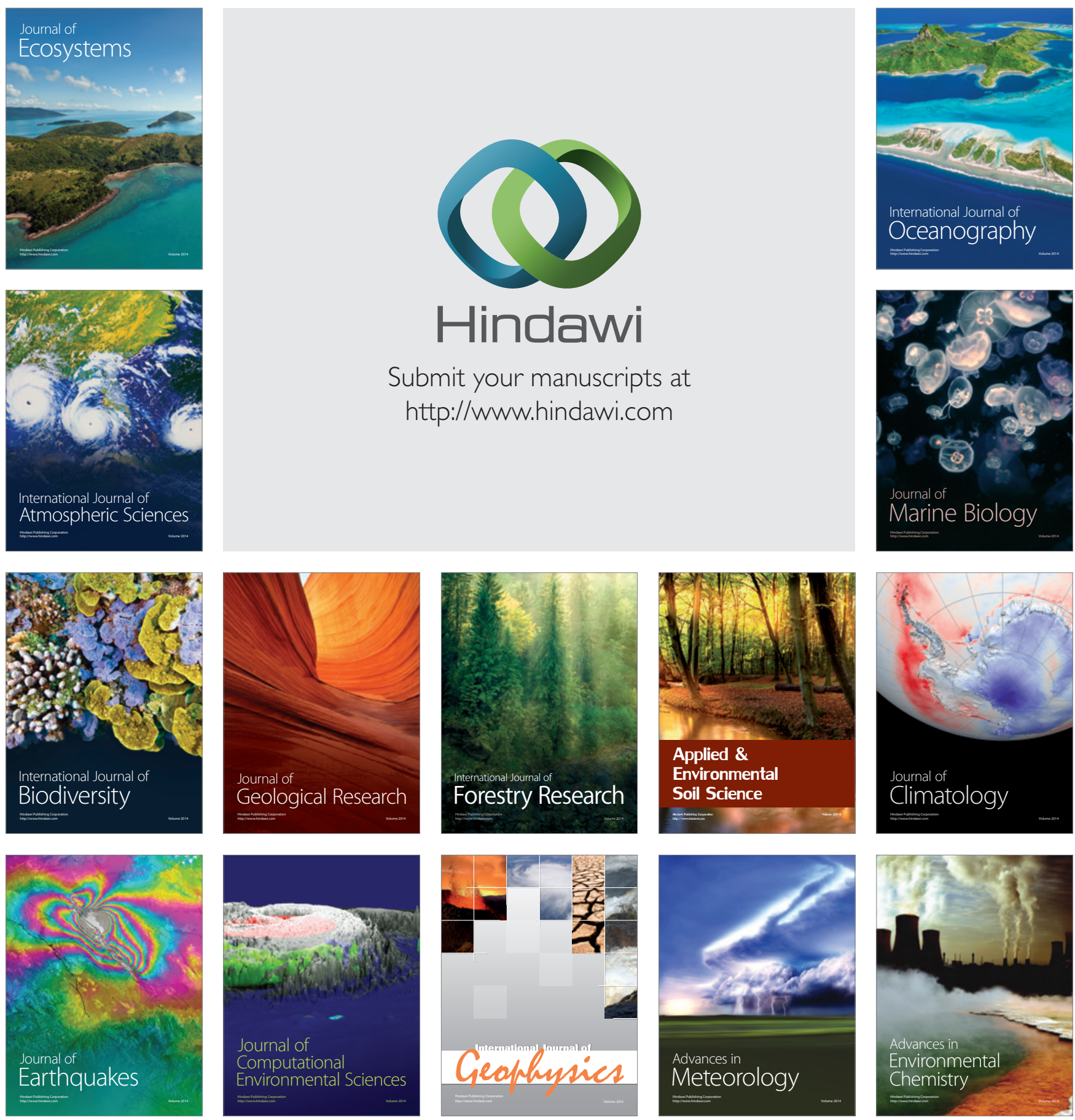